\title{
Edward Berenson, La statue de la Liberté. Histoire d'une icône franco-américaine
}

Paris, Armand Colin, 2012

\section{François Jarrige}

\section{OpenEdition}

Journals

\section{Édition électronique}

URL : https://journals.openedition.org/artefact/8694

DOI : $10.4000 /$ artefact.8694

ISSN : 2606-9245

\section{Éditeur :}

Association Artefact. Techniques histoire et sciences humaines, Presses universitaires du Midi

\section{Édition imprimée}

Date de publication : 11 septembre 2014

Pagination : 206-208

ISBN : 978-2-271-08150-6

ISSN : 2273-0753

\section{Référence électronique}

François Jarrige, «Edward Berenson, La statue de la Liberté. Histoire d'une icône franco-américaine », Artefact [En ligne], 2 I 2014, mis en ligne le 11 mai 2021, consulté le 24 août 2021. URL : http:// journals.openedition.org/artefact/8694; DOI : https://doi.org/10.4000/artefact.8694

Ce document a été généré automatiquement le 24 août 2021.

\section{(c) $(1) \odot$}

Artefact, Techniques, histoire et sciences humaines est mise à disposition selon les termes de la Licence Creative Commons Attribution - Pas d'Utilisation Commerciale - Pas de Modification 4.0 International. 


\title{
Edward Berenson, La statue de la Liberté. Histoire d'une icône franco- américaine
}

Paris, Armand Colin, 2012

\author{
François Jarrige
}

\section{RÉFÉRENCE}

Edward Berenson, La statue de la Liberté. Histoire d'une icône franco-américaine, trad. de l'américain par Marie-Laurence Netter, Paris, Armand Colin, 2012, 255 p.

1 Edward Berenson, spécialiste nord-américain de l'histoire culturelle et politique de la France contemporaine, livre ici une belle réflexion sur plus d'un siècle de relations franco-américaines. Il le fait à partir de l'étude d'une "icône» universellement connue : la statue de la Liberté. Ce vaste monument, devenu le symbole de l'Amérique, a déjà suscité beaucoup de travaux en histoire de l'art comme en histoire des techniques et de l'architecture. Le projet de l'auteur est quelque peu différent; il s'inscrit davantage dans une histoire culturelle cherchant à penser les imaginaires, les représentations et les significations changeantes associés à cette vaste construction, depuis les premiers projets des années 1860-1870 jusqu'à aujourd'hui.

2 Si la statue est inaugurée à New York en 1886, l'idée de l'édifier est bien antérieure. Elle remonte au milieu des années 1860 , lorsque des intellectuels libéraux français réunis autour du juriste Édouard de Laboulaye souhaitent rendre hommage aux États-Unis au lendemain de la guerre de Sécession et de l'assassinat du président Lincoln, alors même que le régime de Napoléon III avait soutenu le Sud. L'idée d'un « don monumental » du peuple français aux États-Unis émerge peu à peu au croisement des enjeux diplomatiques, artistiques, mais aussi socio-économiques, qui caractérisent alors les relations franco-américaines. Dans les premiers chapitres, l'auteur synthétise avec clarté et précision la genèse du monument, comment l'idée d'une statue féminine 
chemine dans différents lieux, comment le sculpteur Bartholdi parvient peu à peu - et non sans difficultés - à intéresser des financeurs en faisant du projet de statue un symbole du resserrement des liens entre la France et les États-Unis. Dans un premier temps, les Américains s'intéressent peu à ce projet de sculpture néo-classique dont ils ne voient pas l'intérêt. Le projet commence à les interpeler lorsque la sculpture change de signification pour devenir "une grande réalisation de la technique moderne" (p. 44), un symbole de la grandeur technologique et industrielle qui s'affirme alors comme le ciment de l'identité nord-américaine. Une souscription, ainsi que divers événements mondains, spectacles populaires, commercialisation d'objets et autre loterie, sont organisés pour intéresser le public à ce projet monumental. La genèse du monument participe pleinement de la culture de masse naissante et des nouvelles stratégies commerciales et médiatiques qui apparaissent de part et d'autre de l'Atlantique. Au début des années 1880 , le million de francs nécessaire au projet est finalement réuni et permet le lancement de la construction.

3 La statue de la liberté fut "un chef d'œuvre de mécanique et de technologie », écrit Berenson (p. 70), et c'est ici qu'intervient le troisième personnage clé de cette histoire : l'ingénieur Gustave Eiffel. La statue est en effet une réalisation remarquable de la nouvelle architecture en fer qui s'impose au XIX ${ }^{e}$ siècle. D'une certaine manière, elle n'est rien de plus qu'une «tour Eiffel moderne revêtue du costume respectable de l'antiquité classique ». Comme les nombreuses gares construites à l'époque, il fallait en effet éviter les scandales en dissimulant la modernité de la structure métallique derrière l'aspect rassurant du drapé antique. L'édification de cette vaste structure de 45 mètres de haut posait divers problèmes techniques et a contraint Eiffel à introduire de nombreuses innovations pour rendre ce monument gigantesque suffisamment robuste pour affronter le vent et les intempéries. Mais son édification ne repose pas seulement sur l'ingéniosité de l'ingénieur Eiffel ; elle mobilise aussi plusieurs centaines d'artisans hautement qualifiés et compétents. Les étapes de la construction ont été abondamment scrutées et photographiées, les artisans ferronniers notamment travaillèrent avec soin les plaques de cuivre qu'ils martelèrent à l'aide de gros maillets en bois. Finalement, la construction du piédestal prit forme à la fin de l'année 1885 et l'inauguration officielle eut lieu le 28 octobre 1886. Berenson montre les ambivalences, les doutes et les controverses qui accompagnent l'arrivée de la statue en territoire américain. Alors que Laboulaye et Bartholdi avaient, par exemple, pensé la statue comme un symbole de l'abolition de l'esclavage, certains représentants de la population noire contestent cette lecture et soulignent combien "l'idée de la "liberté" de ce pays "illuminant le monde", ou même la Patagonie, est tout à fait ridicule " à l'heure où les gens de couleurs du Sud restent persécutés de multiples manières (p. 120), de même des militantes féministes manifestèrent également leur scepticisme à l'égard du monument et de sa symbolique.

4 L'originalité du livre de Berenson est qu'il n'en reste pas, contrairement à beaucoup d'autres travaux, à l'examen de la genèse de la statue, mais qu'il en fait un objet de controverse de longue durée, un enjeu de débat incessant pendant plus d'un siècle. Il suit les imaginaires associés au monument au $\mathrm{xx}^{\mathrm{e}}$ siècle, ses réagencements successifs, au gré des évolutions de la société américaine. La moitié du livre - du chapitre 6 au chapitre 10 consacré au centenaire de 1986 - suit ainsi l'évolution des significations de la statue et son "symbolisme malléable». Beaucoup de ces développements sont passionnants car l'ambivalence et l'ambiguïté de la statue sont ceux-là mêmes qui travaillent la notion de «liberté » elle-même à l'époque contemporaine : le monument 
est-il le symbole de la libre entreprise et du capitalisme triomphant ou celui de l'émancipation des plus pauvres et des opprimés? À la fin du XIX siècle, le débat s'articule ainsi avec la question de l'immigration qui explose aux États-Unis, la statue étant tour à tour décrite comme le symbole d'une société ouverte et accueillante ou, au contraire, comme celui de la triste condition des nouveaux immigrants plongés dans la misère. C'est surtout à partir des années 1930 - lorsque le nombre d'immigrants décline - que la statue s'affirme comme un symbole de l'immigration perçue positivement. Le lustre et l'importance de la statue s'accroissent surtout après 1945, à l'heure du modèle américain triomphant et de la généralisation de la consommation de masse. Le nombre annuel de visiteurs atteint un million en 1964 ; la statue devient peu à peu le principal symbole du pays : elle envahit l'iconographie, les timbres postes, elle est utilisée dans de nombreux produits commerciaux, dans l'imaginaire populaire et la «culture Pop ». Au cours des luttes sociales et politiques des années 1960 et 1970, la statue demeure souvent un enjeu symbolique central: des activistes afro-américains tentent ainsi, en 1964, de faire sauter celle qu'ils nomment la " maudite vieille salope ", alors que des vétérans du Vietnam s'y installent en 1971 pour exiger la fin de la guerre (p. 184-185).

5 L'histoire de la statue devient aussi plus nettement transnationale dans le dernier quart $\mathrm{du} \mathrm{xx}^{\mathrm{e}}$ siècle. Des copies ou des reproductions existent ainsi dans trente-cinq pays - il y en a treize en France, mais d'autres se retrouvent dans des pays aussi différents que le Japon, la Chine, l'Ukraine ou le Brésil. La statue " semble pouvoir s'adapter à l'infini ", écrit Berenson; ses usages et ses appropriations sont très divers selon les contextes, même si l'auteur approfondit peu cette dimension. L'ouvrage est finalement travaillé par une réflexion très contemporaine sur la place des États-Unis dans le monde. La mémoire et l'ombre du 11 septembre 2001 planent d'ailleurs sur le livre et l'analyse s'éloigne parfois - de façon assez étonnante pour un lecteur français - de l'étude proprement historique pour célébrer « la liberté et l'espérance, que les États-Unis ont offertes, [...] bien qu'inégalement, à un grand nombre de gens» (p. 224); l'auteur semble ainsi reprendre sans nuance les discours apologétiques qui voyaient dans la statue le témoignage « du pouvoir de la liberté comme idéal universel ».

\section{AUTEURS}

\section{FRANÇOIS JARRIGE}

Université de Bourgogne, Centre Georges-Chevrier 